\title{
Analysis of Transportation Users' Preferences and Attitudes for Identifying Micro-Level Determinants of Transportation Network Companies' (TNCs) Growth
}

\author{
Sahila Sarjana¹, Ossama E. Ramadan², Virginia P. Sisiopiku1 \\ ${ }^{1}$ Department of Civil, Construction and Environmental Engineering, University of Alabama at Birmingham, Birmingham, \\ AL, USA \\ ${ }^{2}$ CDM Smith Inc., Houston, TX, USA \\ Email: vsisiopi@uab.edu
}

How to cite this paper: Sarjana, S., Ramadan, O.E. and Sisiopiku, V.P. (2020) Analysis of Transportation Users' Preferences and Attitudes for Identifying Micro-Level Determinants of Transportation Network Companies' (TNCs) Growth. Journal of Transportation Technologies, 10, 251-264. https://doi.org/10.4236/jtts.2020.103016

Received: May 20, 2020

Accepted: June 16, 2020

Published: June 19, 2020

Copyright $\odot 2020$ by author(s) and Scientific Research Publishing Inc. This work is licensed under the Creative Commons Attribution International License (CC BY 4.0)

http://creativecommons.org/licenses/by/4.0/

\section{(c) (i) Open Access}

\begin{abstract}
Over the last decade, the popularity of Transportation Network Companies (TNCs) as a mode of travel has been increasing at a steady pace. This trend highlights the importance of identifying the determinants that influence transportation users to adopt TNCs as a preferred mode choice and the impacts of such preferences on their travel patterns and transportation network operation. This paper reports on a recent study undertaken in Birmingham, AL aiming at understanding and documenting the factors that influence transportation users to select TNCs (such as Uber/Lyft) for completing typical day trips. In doing so, a travel diary questionnaire survey was developed in accordance with the Institute of Transportation Engineers (ITE) Manual on Transportation Engineering Studies using the Qualtrics Research Core platform. The questionnaire was used to survey over 450 transportation users in the Birmingham Metro area. The survey participants provided detailed trip information for a typical 24-hr day along with demographic data and travel preference information. The survey responses provide high-resolution micro-level indicators of travel preferences and behaviors in a TNC-served area, which is a much-needed type of information for researchers and transportation planning agencies.
\end{abstract}

\section{Keywords}

Transportation Network Companies (TNC), Travel Preferences,

Mode Choice, Uber/Lyft, Questionnaire Survey,

Travel Patterns 


\section{Introduction}

In the recent years, Transportation Network Companies (TNCs) such as Uber/Lyft have led to an expansion of on-demand app-based ride sourcing transportation options [1]. Despite the rapid growth of several TNC markets, analysis of potential and actual impacts of TNCs presence on preferences and daily travel patterns of TNC-aware transportation system users are still very limited. Such analyses are hindered by the lack of availability of detailed data due to privacy concerns, as well as technical and financial feasibility issues.

The objective of this study is to understand current travel preferences and practices of transportation users in the Birmingham Metropolitan Area and document their attitudes toward TNC use as a travel mode of choice. To meet this objective, we developed a comprehensive travel diary questionnaire survey and used it to survey a TNC-aware population sample of 451 respondents in the Birmingham Metro Area. The survey requested participants to report detailed trip information for a typical day (i.e., 24-hr travel diary) including origin and destination of each trip, travel time, trip purpose and travel mode used. Demographic data were also obtained and used in the analysis and interpretation of survey findings. The analysis helped to identify indicators that contribute to the use of TNCs and, thus, can create a shift in the travel pattern of TNC-aware populations when TNC services are available in a region.

\section{Literature Review}

Transportation Network Companies (TNCs) services were introduced in 2009, as an app-based ride sourcing platform to connect passengers with drivers automate reservations, payments, and customer feedback [1]. In the initial stage, TNCs offered only ride-hailing options [2], but later ride-sharing options were added thus expanding the scope of the service and adding a cost-saving incentive for users. In 2013, the California Public Utilities Commission defined such services as Transportation Network Companies, which provides both ride-hailing (such as Uber/Lyft) and ride-sharing (such as Uber Pool/Lyft-share) options [3].

Examination of the TNC users' demographic characteristics is very important for determining the users' reasons behind using the TNCs. The literature review revealed several earlier studies that examined the demographics of TNC users across United States [4]-[12]. A common characteristic of those users is that they mostly belong in the 18 - 34 years old age group and most of them are highly educated. Though it was initially expected that people with low incomes would be a significant proportion of users of TNCs give the lack of vehicle ownership, studies proved this to be a misconception as the surveys confirmed that TNC customers represent a variety of income levels [4]-[12]. So, the literature review provided some evidence that TNC use is not directly related to income level but rather age, education, as well as the traffic conditions of the region.

Users' perspectives towards transportation modes are a significant identifier of mode selection. A 2019 study on user perspectives showed that "perceived 
value" and "perceived risk" have respectively positive and negative impacts on the travelers' decision about choosing TNCs as their daily mode of travel [13]. Several other studies examined trip purpose and stated that the main purpose of ride-sharing trips in their region was "social/leisure", while other reasons cited related to parking or users' unwillingness to drive [4] [7] [8] [14].

The growth of TNCs has been seen by many skeptics as contributing to traffic congestion as well as threatening the viability of taxi and public transit services. In New York, during peak hours about $7.5 \%$ of trips are performed by TNCs whereas only $4 \%$ are performed by taxis [15]. The literature confirms that technology-enabled services can affect travel behavior in dynamic ways by providing more travel options, reducing travel uncertainty, and potentially replacing other modes [16]. Research by Sivak (2014) states that the percentage of zero-vehicle households may also increase as a result [17]. Moreover, another study states that $40 \%$ of TNC users in San Francisco, CA reported that they use their private vehicle less due to the adoption of on-demand mobility sharing services [2]. In Boston, MA, a recent report by the Boston Metropolitan Planning Organization concluded that introducing TNCs in the Boston area resulted in transit substitution at a rate of $54 \%$ with $12 \%$ occurring during the morning or afternoon commute periods [18].

In sum, the literature review provided some useful insights on TNC use and its impacts on mode choice and travel demand. However, the review also confirmed that case studies on TNC use and impacts are still limited and findings from earlier studies are localized and reflect that characteristics of users in the particular local. Thus a need was identified to conduct a study of travelers' perceptions and use of TNCs in Birmingham. The study was used to document users' attitudes, choices, and behavioral trends and inform about the potential influence of identified technologies on travel behavior and demand. At the time of survey administration, the Birmingham metro area had two Transportation Network Companies providing their services to this region, namely Uber and Lyft. Uber was first launched in this region in January 2015 [19] thus expanding the transportation mode options in the Birmingham market. Two years later, in February 2017, Lyft came to the Birmingham service area [20]. However, both companies only offer ride-hailing services to the users, while ride-sharing services are not yet introduced to this region.

\section{Methodology and Data Collection}

This paper discusses the use of a survey to identify awareness, usage, and proliferation of identified technologies among transportation system users in Birmingham, AL. To capture such data, an online questionnaire survey was designed and used to collect travel preferences, typical trips, and demographic data in accordance with the ITE Manual on Transportation Engineering Studies (ITE, 2011) [21]. First, an approval was obtained from the Institutional Review Board (IRB) for Human Use to proceed with the survey. The Qualtrics Research Core 
tool [22] was used to prepare the questionnaire as it provided a user-friendly platform. The questionnaire was modified at various stages and was pretested and fine-tuned prior to use to ensure that it was easy for responders to understand the questions and provide answers.

The questionnaire asked transportation users about their preferences towards using TNCs, the frequency of use, reason for selection along with demographic information such as gender, age, annual income, education level, and vehicle ownership. The criteria for collecting the demographic data were adopted from the Census criteria. Moreover, the questionnaire solicited detailed 24-hr trip information of the respondents on a typical day. In the determination of the exact locations of origin and destination of the trips on 24-hr travel diary, we used Google maps API key application. This allowed respondents to easily insert the location of their origins and destinations.

The survey was administered in the Birmingham, AL region between December 2018 and January 2019. The study site comprises of the cities of Birmingham, Homewood, Vestavia Hills, Mountain Brook, and Hoover. Figure 1 shows the 29 residential ZIP codes that we selected as our survey zones along with the exact location of each study respondent. Given a population of $1,141,309$ capita in the Birmingham Metro Area as per the 2016 Census data [23], a sample of 400 responses was deemed sufficient according to the formula shown in the Equation (1) for calculating standard population sample size.

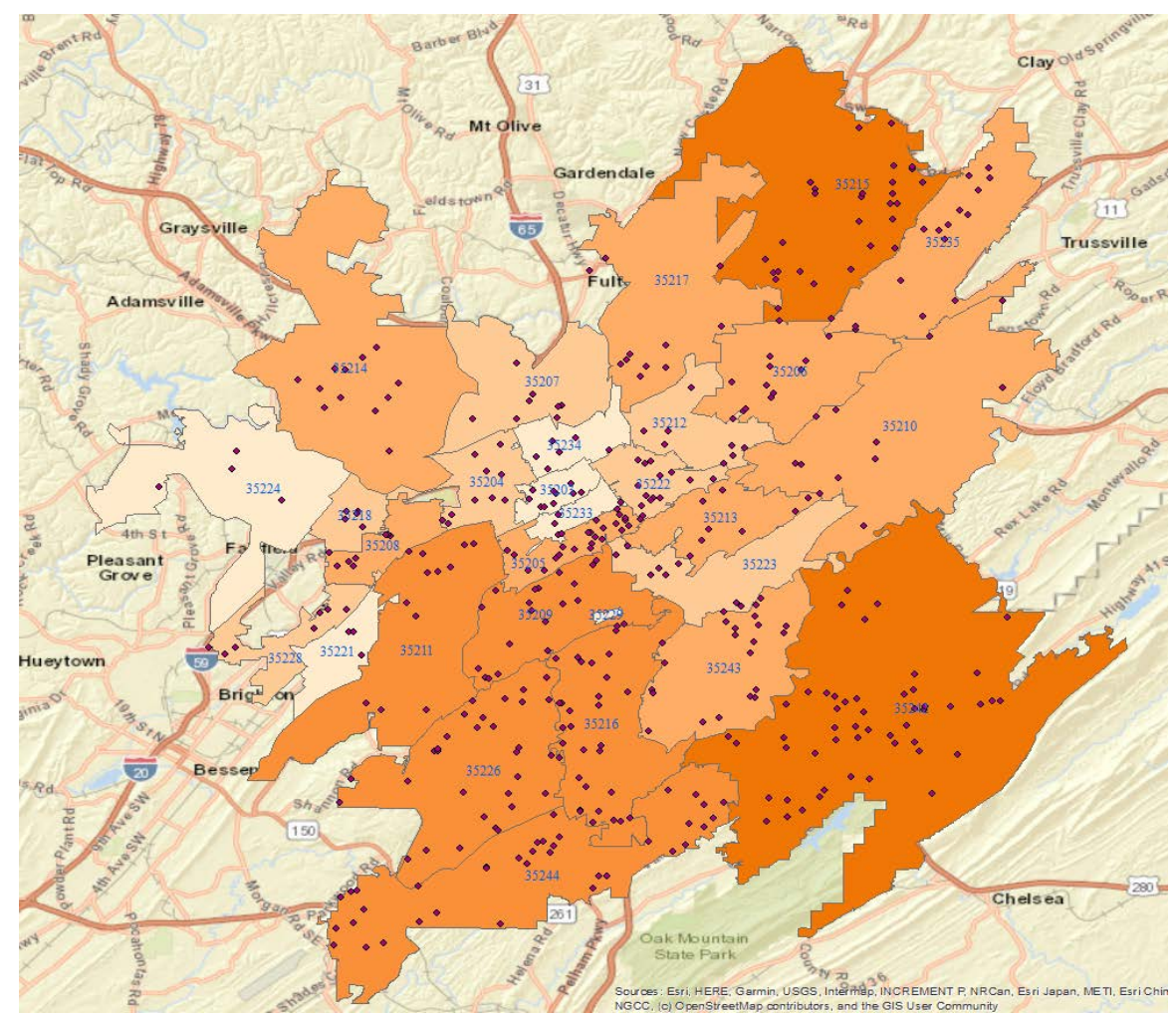

Figure 1. Survey area showing ZIP codes (by number), and respondents locations (by dot). 


$$
n=\frac{\frac{z^{2} \times p(1-p)}{e^{2}}}{1+\left(\frac{z^{2} \times p(1-p)}{e^{2} N}\right)}
$$

where $n$ is the sample size, $z$ is the $z$-score for the corresponding confidence interval, $e$ is the margin of error, $N$ is the population size as per latest Census reports, and $p$ is the standard deviation (assumed to be equal to 0.5 ).

The research team through a detailed data verification to process to check the responses received using ArcGIS software [24], built-in tests, and through close manual observation. Several responses were deducted from the database and new responses were collected to replace those that did not pass validation tests or showed mismatch of reported data. A final database of 451 responses from Birmingham Metro Area was used in the analysis of this paper. A brief about the database is given on Table 1 .

\section{Results and Discussions}

Among the 451 responders considered in the analysis, 342 were women and the remaining were men. The overrepresentation of women in the survey was noted but is not alarming as many surveys reported higher numbers of survey participants as being female. The responders provided details for 1023 trips performed over a 24 -hr period. Analysis of the data showed that approximately $6.37 \%$ of the reported trips were conducted by TNCs, with 73\% of TNC trips performed by female responders. Taking exposure into consideration, the finding indicates that TNCs are used almost at the same rate among female and male transportation users in the Birmingham region.

\subsection{Preferences towards TNCs}

To understand the survey participants' mode choices and their exposure to modes of transportation other than automobile we asked them whether they have used TNCs, public transit, bicycle, ride-sharing program, etc. in the past year. As shown in Figure 2, approximately $45 \%$ of survey participants indicated that they have used TNCs in the past year. This is an important finding given that only $21 \%$ reported use of public transit during the same period and $12.6 \%$ of bicycle.

To understand the frequency of TNC use, the respondents were asked when was the last time that they used TNCs in the Birmingham region. Analysis of survey responses revealed that $50 \%$ of the TNC users used TNCs within the past month and half of those (about 24.3\%) used TNCs at least once within the 7 days preceding the survey.

Additional analysis was performed to determine the potential impact of age on TNCs selection. Table 2 provides a cross-tabulation of survey results indicating the frequency of TNC use by age bracket. It can be observed that 25 to 34 years old survey participants use the TNCs the most (about 27.14\%) followed by 18 to 25 years old responders (19.5\%). It can be also observed that use of TNC drops steadily as age increases when considering middle aged and elderly users. 
Responders were also asked to note the reason(s) for using TNCs in the past. In order to identify the most influential reasons for selecting TNC services as a mode of transportation, we factorized each reason to take a value of 1 if selected, and 0 if not selected. Table 3 documents the mean and standard deviation selection according to the survey responses. The results show that convenience was reported as the main driving force for the selection of TNCs as a mode of transportation. Safety/avoiding driving when intoxicated and lack of automobile availability were cited as the second and third most important reasons for use of TNCs in the survey of Birmingham users.

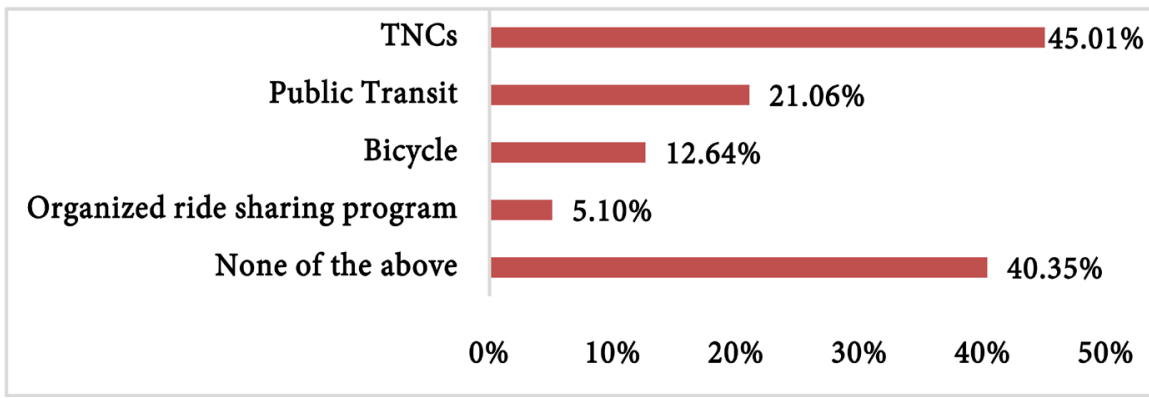

Figure 2. Modes used in the past year by the survey participants.

Table 1. Summary of survey responses data.

\begin{tabular}{cc}
\hline Item & Details \\
\hline Data Collection Period & Nov 2018-Jan 2019 \\
Total Responses & 451 \\
Total Numbers of Trips & 1023 \\
Number of TNC Trips & 69 \\
Average Travel Time per Trip & 25.64 minutes \\
\hline
\end{tabular}

Table 2. Frequency of TNC using at different age level.

\begin{tabular}{cccccccc}
\hline $\begin{array}{c}\text { Age versus TNC } \\
\text { Use Frequency }\end{array}$ & $\begin{array}{c}\text { Within the } \\
\text { past seven } \\
\text { days }\end{array}$ & $\begin{array}{c}\text { Within the } \\
\text { past 30 days }\end{array}$ & $\begin{array}{c}\text { Within the } \\
\text { past two } \\
\text { months }\end{array}$ & $\begin{array}{c}\text { Within the } \\
\text { past six } \\
\text { months }\end{array}$ & $\begin{array}{c}\text { Within the } \\
\text { past year }\end{array}$ & Total \\
\hline 18 to 24 years & $6.67 \%$ & $3.81 \%$ & $0.95 \%$ & $6.19 \%$ & $1.90 \%$ & $19.52 \%$ \\
25 to 34 years & $4.76 \%$ & $8.57 \%$ & $5.71 \%$ & $5.24 \%$ & $2.86 \%$ & $\mathbf{2 7 . 1 4 \%}$ \\
35 to 44 years & $3.33 \%$ & $3.81 \%$ & $1.43 \%$ & $5.24 \%$ & $3.81 \%$ & $17.62 \%$ \\
45 to 54 years & $5.24 \%$ & $4.29 \%$ & $1.43 \%$ & $1.43 \%$ & $3.81 \%$ & $16.19 \%$ \\
55 to 64 years & $1.90 \%$ & $4.29 \%$ & $0.00 \%$ & $2.86 \%$ & $1.43 \%$ & $10.48 \%$ \\
65 to 74 years & $2.38 \%$ & $2.38 \%$ & $0.48 \%$ & $1.43 \%$ & $1.43 \%$ & $\mathbf{8 . 1 0 \%}$ \\
75 years and over & $0.00 \%$ & $0.00 \%$ & $0.00 \%$ & $0.48 \%$ & $0.00 \%$ & $\mathbf{0 . 4 8 \%}$ \\
\hline
\end{tabular}


Table 3. Mean (Standard Deviation) of the factors affecting the TNC preference.

\begin{tabular}{|c|c|c|c|c|c|c|}
\hline Reasons & $\begin{array}{l}\text { Within the past } \\
\text { seven days }\end{array}$ & $\begin{array}{l}\text { Within the past } \\
\text { thirty days }\end{array}$ & $\begin{array}{l}\text { Within the past } \\
\text { two months }\end{array}$ & $\begin{array}{l}\text { Within the past } \\
\text { six months }\end{array}$ & $\begin{array}{l}\text { Within the } \\
\text { past year }\end{array}$ & Total \\
\hline Convenience & $0.13(0.33)$ & $0.15(0.36)$ & $0.07(0.25)$ & $0.14(0.35)$ & $0.07(0.26)$ & $0.56(0.5)$ \\
\hline Safety/to avoid driving under the influence & $0.07(0.26)$ & $0.09(0.29)$ & $0.03(0.17)$ & $0.06(0.23)$ & $0.05(0.22)$ & $0.30(0.46)$ \\
\hline Car is not available & $0.07(0.26)$ & $0.06(0.24)$ & $0.05(0.22)$ & $0.06(0.24)$ & $0.02(0.15)$ & $0.27(0.44)$ \\
\hline Destination has little or no parking availability & $0.06(0.23)$ & $0.08(0.27)$ & $0.02(0.14)$ & $0.06(0.23)$ & $0.03(0.18)$ & $0.24(0.43)$ \\
\hline Cheaper than other alternatives & $0.05(0.22)$ & $0.05(0.22)$ & $0.01(0.12)$ & $0.07(0.25)$ & $0.02(0.15)$ & $0.21(0.41)$ \\
\hline Parking at destination is expensive & $0.06(0.24)$ & $0.05(0.21)$ & $0.01(0.12)$ & $0.05(0.21)$ & $0.01(0.12)$ & $0.19(0.39)$ \\
\hline Transit is not accessible & $0.02(0.14)$ & $0.01(0.12)$ & $0.01(0.10)$ & $0.01(0.10)$ & $0.00(0.07)$ & $0.06(0.23)$ \\
\hline Transit is not reliable & $0.02(0.14)$ & $0.01(0.10)$ & $0.00(0.00)$ & $0.00(0.00)$ & $0.00(0.00)$ & $0.03(0.17)$ \\
\hline Other reason & $0.01(0.10)$ & $0.01(0.10)$ & $0.00(0.07)$ & $0.00(0.07)$ & $0.00(0.07)$ & $0.03(0.18)$ \\
\hline Other modes are not available & $0.00(0.00)$ & $0.01(0.10)$ & $0.00(0.07)$ & $0.00(0.07)$ & $0.00(0.07)$ & $0.02(0.15)$ \\
\hline
\end{tabular}

\subsection{Transportation Network Companies (TNCs) Trip Characteristics}

Cross tabulation of trip purpose to trip mode in Table 4 shows that most of the trips conducted by TNCs are trips to work or to home. This is consistent across the other available modes, including the automobile. The results also indicate that responders use TNC services often for dining out and late-night entertainment. In fact, when accounting for the number of trips performed by each mode, the percentage of trips made for eating out/take out/nightlife with TNCs was found to be $22 \%$, far greater than the same reported for automobile trips ( $11 \%$ of total). This shows a stronger preference for use of TNCs over automobile for dining out and entertainment trips among the Birmingham survey responders. This is consistent with findings in the literature suggesting that the greatest levels of TNC use are on Friday and Saturday evenings and the busiest time in most cities is between $7 \mathrm{pm}$ and midnight [25].

The documentation of trips undertaken during a typical day 24-hr travel diary by the 451 Birmingham questionnaire survey respondents provide trip details for 1023 trips. As shown in Table 4 over $85 \%$ of these trips were conducted by private automobile and $6.3 \%$ by TNCs (i.e., Uber and Lyft). The data are consistent with earlier large-scale surveys in the Birmingham region by Sisiopiku [26] [27] which reported that over $88 \%$ of UAB employees and $82 \%$ of UAB students commute to $\mathrm{UAB}$ by private automobile.

We also broke down the results according to the percentage of TNC users and non-users as shown in Table 5. We observed that nearly $78 \%$ of TNC users own a vehicle, just $3 \%$ less that the $81 \%$ of non-TNC users that reported vehicle ownership.

Figure 3 represents the distribution of TNC trips by purpose and available TNC option. Two TNC companies operate in Birmingham, namely Uber and Lyft. TNC users in the Birmingham Metro Area reported using Uber for more than $80 \%$ of TNC trips. This is expected, given that Uber services have been available for longer 
Table 4. Trip purpose vs trip mode.

\begin{tabular}{ccccccccc}
\hline Trip Purpose to Trip Mode & Car & TNCs & Carpool/Vanpool & Car Rental & Taxi & Transit & Bike & Walk \\
\hline Home & $27.2 \%$ & $1.6 \%$ & $0.5 \%$ & $0.3 \%$ & $0.4 \%$ & $0.5 \%$ & $0.1 \%$ & $0.4 \%$ \\
Work & $18.4 \%$ & $2.4 \%$ & $0.4 \%$ & $0.0 \%$ & $0.2 \%$ & $0.7 \%$ & $0.1 \%$ & $0.4 \%$ \\
School & $2.8 \%$ & $0.3 \%$ & $0.1 \%$ & $0.0 \%$ & $0.0 \%$ & $0.4 \%$ & $0.1 \%$ & $0.6 \%$ \\
Eat/Take-out & $6.7 \%$ & $0.5 \%$ & $0.4 \%$ & $0.1 \%$ & $0.0 \%$ & $0.0 \%$ & $0.1 \%$ & $0.4 \%$ \\
Nightlife/Bar & $1.2 \%$ & $0.4 \%$ & $0.2 \%$ & $0.2 \%$ & $0.0 \%$ & $0.0 \%$ & $0.0 \%$ & $0.0 \%$ \\
Shopping-Grocery & $8.8 \%$ & $0.3 \%$ & $0.2 \%$ & $0.0 \%$ & $0.0 \%$ & $0.1 \%$ & $0.0 \%$ & $0.8 \%$ \\
Shopping-Retail & $6.9 \%$ & $0.3 \%$ & $0.0 \%$ & $0.0 \%$ & $0.0 \%$ & $0.2 \%$ & $0.0 \%$ & $0.1 \%$ \\
Services (e.g. bank, post office) & $7.1 \%$ & $0.2 \%$ & $0.4 \%$ & $0.0 \%$ & $0.1 \%$ & $0.3 \%$ & $0.0 \%$ & $0.2 \%$ \\
Pick-up passenger & $3.4 \%$ & $0.0 \%$ & $0.1 \%$ & $0.0 \%$ & $0.0 \%$ & $0.0 \%$ & $0.0 \%$ & $0.0 \%$ \\
Drop-off passenger & $2.8 \%$ & $0.4 \%$ & $0.1 \%$ & $0.0 \%$ & $0.0 \%$ & $0.0 \%$ & $0.0 \%$ & $0.0 \%$ \\
Total & $\mathbf{8 5 . 3} \%$ & $\mathbf{6 . 3} \%$ & $\mathbf{2 . 3} \%$ & $\mathbf{0 . 5} \%$ & $\mathbf{0 . 6 \%}$ & $\mathbf{1 . 9} \%$ & $\mathbf{0 . 3} \%$ & $\mathbf{2 . 8} \%$ \\
\hline
\end{tabular}

Table 5. Car Availability vs TNC use.

\begin{tabular}{|c|c|c|}
\hline Car Availability & $\begin{array}{l}\text { TNC } \\
\text { User }\end{array}$ & $\begin{array}{c}\text { TNC } \\
\text { Non-user }\end{array}$ \\
\hline I do not own or have regular access to a car & $10.95 \%$ & $5.81 \%$ \\
\hline $\begin{array}{l}\text { I have regular access to a vehicle that someone else in my household } \\
\qquad \text { owns }\end{array}$ & $11.43 \%$ & $13.28 \%$ \\
\hline I own a car & $77.62 \%$ & $80.91 \%$ \\
\hline
\end{tabular}

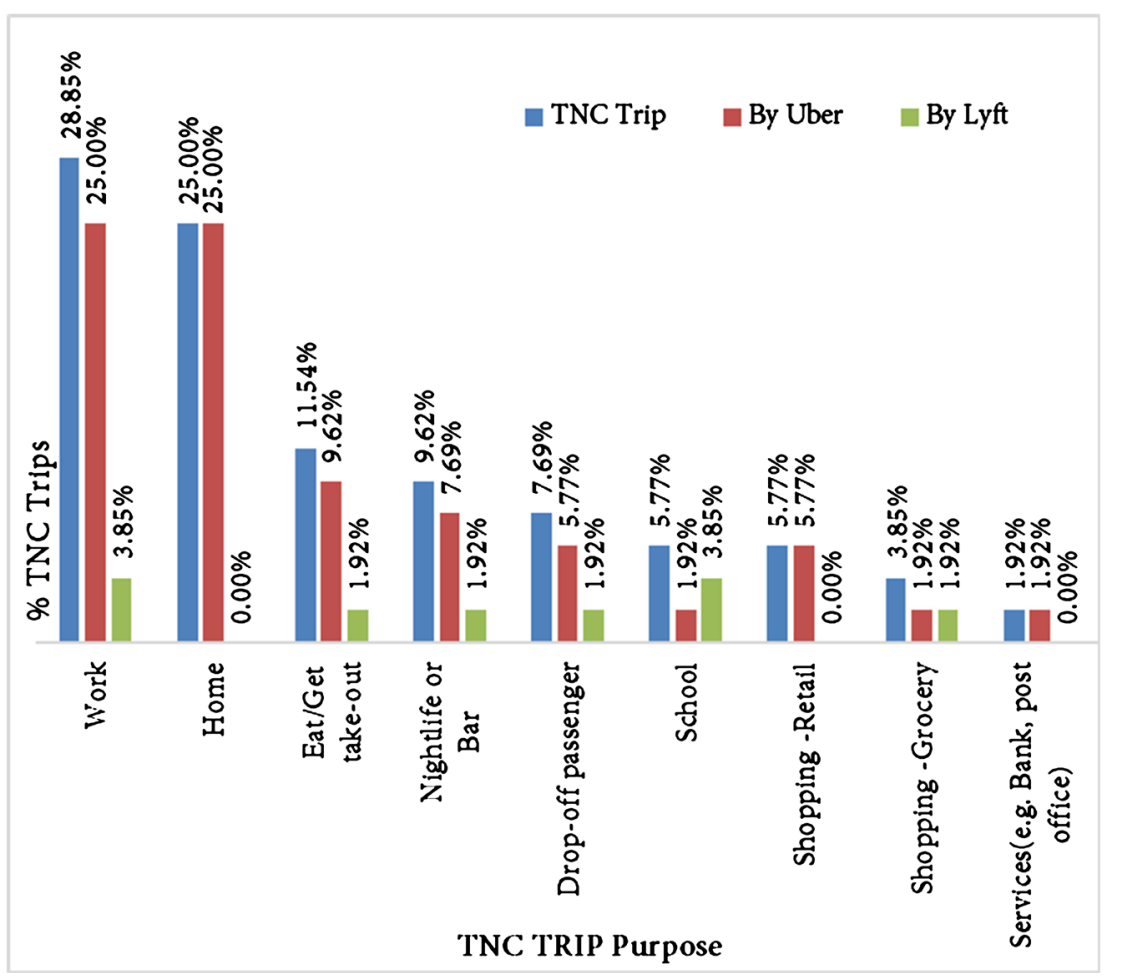

Figure 3. Trip purpose of the TNC trips and the preferred company. 
time in the Birmingham region than Lyft. The finding is also consistent with national data reporting that Uber has largely dominated the market since its 2009 inception, accounting for over $80 \%$ of the market share, though recently this proportion has dropped below $75 \%$ [28].

As mentioned earlier, TNC availability in a transportation market is believed to have a potential impact on the public transportation use. Studies of six individual locations across North American found that between 13.5\% and 54\% of carsharing participants take public transit more frequently. However, one study of approximately 9500 participants across North America found a slight shift away from public transit ridership [29]. To understand the connection between auto ownership, transit users and TNC use, we classified the TNC trips reported in the Birmingham survey by vehicle ownership/availability and trip purpose. The results are depicted in Figure 4.

It can be observed that $52 \%$ of TNC users that completed the Birmingham survey own a vehicle and still use TNCs for select trip purposes. Another 25\% reported that they do not own an automobile, but one is available in their household, while the remaining $23 \%$ of TNC users reported no vehicle ownership or access. These majorities of this $23 \%$ TNC users were public transit users before the introduction of TNCs in Birmingham Metro Area. Thus, distinct types of mode users including the private car users and public transit users are adapting and preferring TNCs as their trip mode.

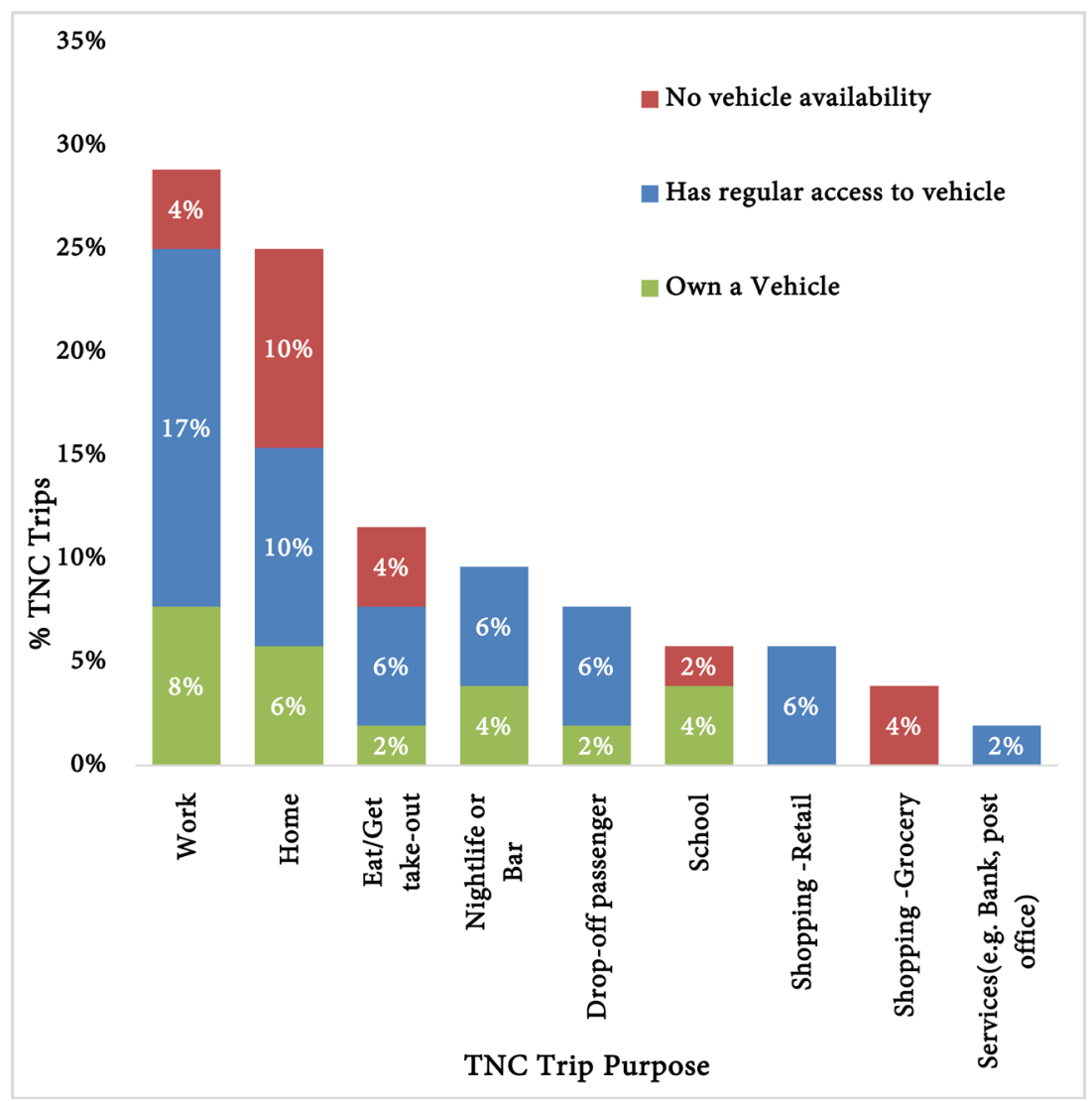

Figure 4. Car availability of TNC users. 
A factor that was considered as a potential determinant of TNC use was the trip distance. According to the characteristics of the TNC trips reported in our study, TNC users use TNC services for trips under 10 miles. A comparison between TNC and non-TNC trips revealed that the average trip length performed by TNC was 5.19 miles, far lower than the average trip length of automobile trips (9.28 miles) in the region. Further analysis indicated that the longest TNC trips involved drop-off of a passenger or trips to work or home. The average trip length per trip purpose for TNC trips is shown in Figure 5.

Similarly, analysis of travel times reported in the survey of the Birmingham transportation system users indicated that the average trip by TNC was 25.64 minutes long, whereas automobile trips averaged 28.38 minutes. This is consistent with findings of the 2013 American Community Survey commuter data for the Birmingham-Hoover Metro Area, which reported average commute in the Birmingham metro of 25.7 minutes.

If we further breakdown the day-time trips and night-time trips into waiting time and available vehicle showing on the app, the responses received show that $88.46 \%$ of TNC users that responded to our survey noted that only 1 - 2 vehicles were available (Table 6). This indicates the limitation of TNC service on Birmingham metro area, which differentiates TNC use in the region compared to large metropolitan areas that performed similar studies such as San Francisco, Boston, and New York to name a few. When considering waiting time, most of the TNC Birmingham riders noted that they had to wait 0 - 5 minute for a vehicle to arrive but one third of all TNC riders reported waiting for 6 - 10 minutes.

The findings of the survey also helped us to define the profile of the typical TNC user in the Birmingham region as a 25 - 34 years old that is using the service for commuting trips or for entertainment purposes for short to medium range distances (or average of 5 miles).

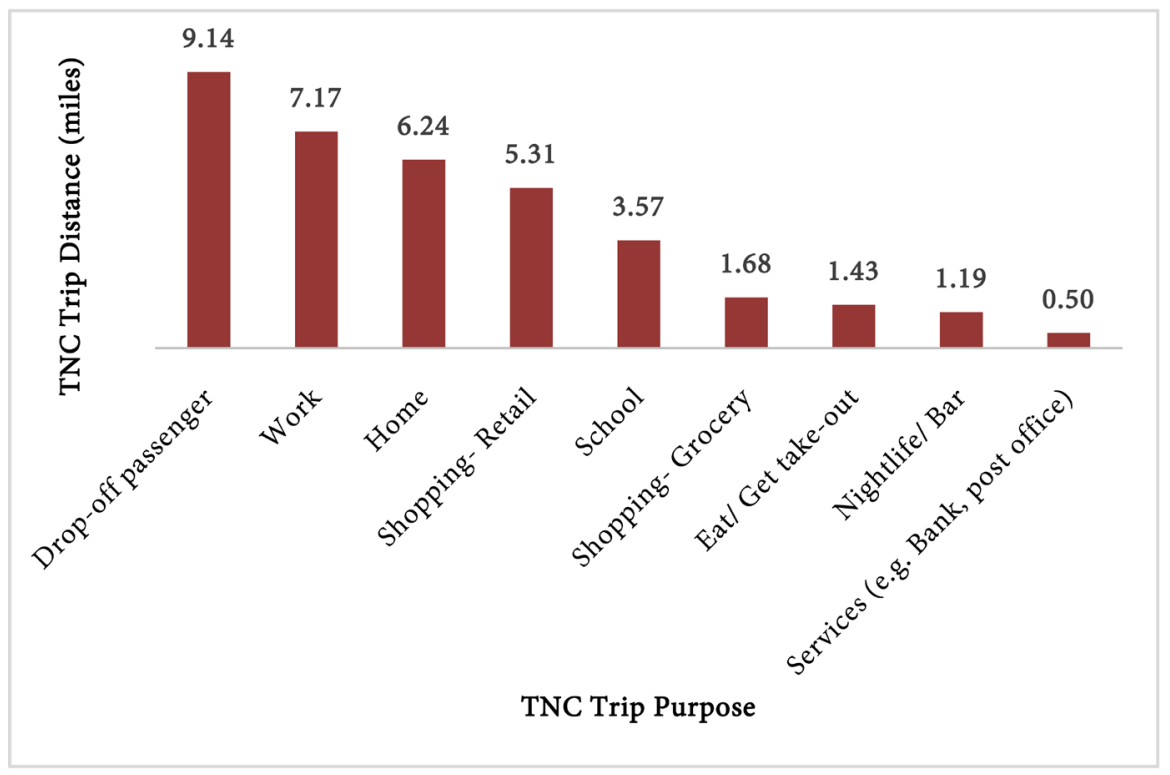

Figure 5. TNC trip distance (miles) for various trip purposes. 
Table 6. Correlation of TNC trip time with waiting time and vehicle availability on app.

\begin{tabular}{cccc}
\hline Available vehicles on App & $\mathbf{1 - 2}$ & $\mathbf{3 - 5}$ & Total \\
\hline Day-time trips & $\mathbf{3 8 . 4 6 \%}$ & $\mathbf{1 1 . 5 4 \%}$ & $\mathbf{5 0 . 0 0 \%}$ \\
0 - 5 minute & $19.23 \%$ & $5.77 \%$ & $25.00 \%$ \\
$11-15$ minutes & $3.85 \%$ & $3.85 \%$ & $7.69 \%$ \\
6 - 10 minutes & $15.38 \%$ & $1.92 \%$ & $17.31 \%$ \\
Night-time trips & $\mathbf{5 0 . 0 0 \%}$ & $\mathbf{0 . 0 0 \%}$ & $\mathbf{5 0 . 0 0 \%}$ \\
0 - 5 minute & $32.69 \%$ & $0.00 \%$ & $32.69 \%$ \\
6 - 10 minutes & $17.31 \%$ & $0.00 \%$ & $17.31 \%$ \\
Total & $\mathbf{8 8 . 4 6 \%}$ & $\mathbf{1 1 . 5 4 \%}$ & $\mathbf{1 0 0 . 0 0 \%}$ \\
\hline
\end{tabular}

\section{Conclusions and Recommendations}

The analysis of 451 questionnaire surveys of Birmingham transportation system users shed light on users' awareness, and use of TNC services in the region. Examination of over 1000 reported trips indicated that approximately $6.3 \%$ of those trips were performed using TNCs, with Uber having $80 \%$ of the TNC market share. Determinants that make TNCs a preferable mode to travelers include convenience of use, and reduction of concerns for traffic safety (especially for late night trips to bars and eating establishments). Lack of parking availability at destination was also listed as a reason for selecting TNCs as a mode of travel.

Examination of respondents' demographics and cross tabulation analyses provided evidence that TNC users cover a wide range of age groups, with younger users being overrepresented compared to elderly. Lack of vehicle availability was associated with only a quarter of all reported TNCs, thus indicating that the majority of TNC users select TNC services as a mode of choice for certain trips.

The analysis also confirmed that the market share of TNC trips is small $(6.3 \%$ of trips reported). This is consistent with expectations, given that Uber and Lyft were recently introduced in the region and that transportation users in the Birmingham Metro still largely embrace the automobile-dependent commuting culture. Still, $45 \%$ of survey responders reportedly have used TNC in the past year, an indication of awareness of TNC service availability. This population segment can be targeted with marketing plans and incentives to encourage mode switching to shared modes, including TNCs.

This paper is the first attempt to document the preferences, attitudes, and choices of transportation users in the Birmingham area in the presence of TNC services. The study highlights links between TNC service availability and travel choices among adults in the region, where the auto-dependent built environment likely influences these links. This study is also significant for providing transportation agencies the means to better-plan mobility as a service (MaaS) where car/ride-sharing platforms are active. Moreover, study findings can inform TNCand other shared-mode services about the needs and opportunities of the local market and enable them to better understand how the travel behavior, mode-choice, 
and travel demand might affect the use of TNCs in the future. The results reported in this paper are also expected to help transit agencies, and TNC companies to coordinate their efforts towards achieving integrated system operations that could attract new customers and benefit both types of transportation services in the future.

Future studies can expand the survey sample size and include new and emerging modes like UberPool and LyftShare. In particular, some attention should be given to "Via", a new TNC option for dynamic ride sharing that was introduced to Birmingham as a pilot program after the completion of this survey. "Via" covers a small radius of service in the Birmingham region and is an app-based vanpool program that operates on a small fee. Analysis of "Via" service information and comparison of Uber and Lyft ridership data before and after the introduction of "Via" could provide valuable information about the interest of Birmingham transportation users for a service like "Via" and its substitution effect on TNC trips in the region. It is further recommended that future studies perform a spatial autocorrelation analysis to confirm that the survey responses are not spatially biased.

\section{Acknowledgements}

The study was conducted under the US DOT-STRIDE/ALDOT sponsored project "Technology Influence on Travel Demand and Behavior".

\section{Conflicts of Interest}

The authors declare no conflicts of interest regarding the publication of this paper.

\section{References}

[1] Shared Mobility Definitions (2020). https://www.transit.dot.gov/regulations-and-guidance/shared-mobility-definitions

[2] Rayle, L., Shaheen, S., Chan, N., Dai, D. and Cevero, R. (2014) App-Based, On-Demand Ride Services: Comparing Taxi and Ride-Sourcing Trips and User Characteristics in San Franscisco. Transportation Sustainability Research Center, University of California, Berkeley.

[3] Transportation Network Companies (2013). https://www.cpuc.ca.gov/tncinfo

[4] Lavieri, P. and Bhat, C.R. (2019) Investigating Objective and Subjective Factors Influencing the Adoption, Frequency, and Characteristics of Ride-Hailing Trips. Transportation Research Part C: Emerging Technologies, 105, 100-125. https://doi.org/10.1016/j.trc.2019.05.037

[5] Rayle, L., Dai, D., Chan, N., Cervero, R. and Shaheen, S. (2016) Just a Better Taxi? A Survey-Based Comparison of Taxis, Transit, and Ridesourcing Services in San Francisco. Transport Policy, 45, 168-178. https://doi.org/10.1016/j.tranpol.2015.10.004

[6] Circella, G.H., Alemi, K.H., Tiedeman, S.H. and Mokhtarian, P.H. (2018) The Adoption of Shared Mobility in California and Its Relationship with Other Components of Travel Behavior.

[7] Clewlow, R.R. and Mishra, G.S. (2017) Disruptive Transportation: The Adoption, Utilization, and Impacts of Ride-Hailing in the United States. 
[8] Chen, Z. (2015) Impact of Ride-Sourcing Services on Travel Habits and Transportation Planning. http://d-scholarship.pitt.edu/25827

[9] Vinayak, P.F., Dias, F.F., Astroza, S.F., Pendyala, R.F. and Garikapati, V.M. (2018) Accounting for Multidimensional Dependents among Decision-Makers within a Generalized Model Framework: An Application to Understanding Shared Mobility Service Usage Levels. Transport Policy, 77, 129-137. https://doi.org/10.1016/j.tranpol.2018.09.013

[10] Dias, F.F., Lavieri, P.S., Garikapati, V.M., Astroza, S., Pendyala, R.M. and Bhat, C.R. (2017) A Behavioral Choice Model of the Use of Car-Sharing and Ridesourcing Services. Transportation, 44, 1307-1323. https://doi.org/10.1007/s11116-017-9797-8 https://link.springer.com/article/10.1007/s11116-017-9797-8

[11] Sikder, S. (2019) Who Uses Ride-Hailing Services in the United States? Transportation Research Board, 2673, 40-54. https://doi.org/10.1177/0361198119859302

[12] Schaller, B. (2018) The New Automobility: Lyft, Uber and the Future of American Cities. Schaller Consulting, Brooklyn.

[13] Wang, Y., Gu, J., Wang, S. and Wang, J. (2019) Understanding Consumers' Willingness to Use Ride-Sharing Services: The Roles of Perceived Value and Perceived Risk. Transportation Research Part C, 105, 504-519. https://doi.org/10.1016/j.trc.2019.05.044

[14] Vanderschuren, M. and Baufeldt, J. (2018) Ride-Sharing: A Potential Means to Increase the Quality and Availability of Motorised Trips while Discouraging Private Motor Ownership in Developing Cities? Research in Transportation Economics, 69, 607-614. https://doi.org/10.1016/j.retrec.2018.03.007

[15] Bialik, C., Flowers, A., Fishcher-Baum, R. and Mehta, D. (2015) Uber Is Serving New York's Outer Boroughs More than Taxis Are. ABC News. https://fivethirtyeight.com/features/uber-is-serving-new-yorks-outer-boroughs-mor e-than-taxis-are

[16] Alemi, F., Circella, G., Handy, S. and Mokhtarian, P. (2018) Use Uber? Exploring the Factors Affecting the Adoption of On-Demand Ride Services in California. Travel Behavior and Society, 13, 88-104. https://doi.org/10.1016/j.tbs.2018.06.002

[17] Sivak, M. (2014) Has Motorization in the Us Peaked? Part 4: Households without as Light-Duty Vehicle. Transport Research Institute, University of Michigan, Ann Arbor.

[18] Gehrke, S.R., Felix, A. and Reardon, T. (2018) Fare Choices: A Survey of Ride-Hailing Passengers in Metro Boston. Boston Metropolitan Planning Organization, Boston.

[19] Ganucheau, A. (2015) Uber Launches in Birmingham. AL.com. https://www.al.com/news/birmingham/2015/12/uber_launching_in_birmingham_t.html

[20] Harris, S. (2017) Lyft Launches in Birmingham. WBRC.

[21] Institute of Transportation Engineers (ITE) (2011) Manual of Transportation Engineering Studies (2nd Edition, Vol. 12).

[22] Qualtrics Research Core (2019). https://www.qualtrics.com/survey

[23] U.S. Census Bureau (2016) 2013 American Community Survey 1-Year Estimates. https://www.census.gov/content/dam/Census/newsroom/press-kits/2014/20140911 _acs1yr2013_webinar.pdf

[24] ArcMap 10.1 (2019). https://www.esri.com/en-us/home

[25] Feigon, S. and Murphy, C. (2018) TCRP Research Report 195: Broadening Understanding of the Interplay among Public Transit, Shared Mobility, and Personal Automobiles. The National Academies Press, Washington DC. https://doi.org/10.17226/24996 
[26] Sisiopiku, V. (2018) Travel Patterns and Preferences of Urban University Students. Athens Journal of Technology \& Engineering, 5, 19-31. https://doi.org/10.30958/ajte.5-1-2

[27] Sisiopiku, V.P. and Ramadan, O.E. (2017) Understanding Travel Behavior and Mode Choice of Urban University Campus Employees. Proceedings of the 58th Transportation Research Forum Annual Conference, Chicago, 20-21 April 2017, 1-13.

[28] Cortright, J. (2017) City Observatory. Uber and Lyft: A Dynamic Duo (Poly)? http://cityobservatory.org/uber-and-lyft-a-dynamic-duopoly

[29] Martin, E. and Shaheen, S. (2010) Greenhouse Gas Emission Impacts of Carsharing in North America. IEEE Transactions on Intelligent Transportation Systems, 12, 1074-1086. https://doi.org/10.1109/TITS.2011.2158539 